\title{
Chest Reconstruction in Thoracic Dystrophy
}

\author{
N. D. BARNES, D. HULL, A. D. MILNER, and D. J. WATERSTON \\ From The Hospital for Sick Children, Great Ormond Street, London
}

\begin{abstract}
Barnes, N. D., Hull, D., Milner, A. D., and Waterston, D. J. (1971). Archives of Disease in Childhood, 46, 833. Chest reconstruction in thoracic dystrophy. Enlargement of the thoracic cage by splitting of the sternum and fixation with bone grafts proved a life-saving measure in a child with thoracic dystrophy and severe respiratory failure whose condition was deteriorating in spite of artificial ventilation. Supported ventilation has, however, remained necessary chiefly because of difficulty in achieving adequate stablity of the thoracic cage.
\end{abstract}

Thoracic dystrophy is a familial chondrodystrophy which chiefly affects the costochondral junctions, and therefore the growth of the ribs, with the result that the chest cage is small and rigid (Jeune, Beraud, and Carron, 1955). The majority of the patients described have died within the first year of life as a result of the chest deformity. In a previous report (Barnes, Hull, and Symons, 1969) we reviewed the published cases and described two children with this condition. The mother of one child showed similar but less severe skeletal changes. Postmortem studies on this child, a boy who died of asphyxia at the age of 6 weeks, showed that in spite of the small chest cage, the lungs were not hypoplastic, and it was concluded that a surgical attempt to enlarge the chest cage would have been justified. A subsequent child of the same family, this time a girl, had a similar chest deformity. This paper reports the results of surgical procedures used to enlarge her rib cage.

\section{Case Report}

This child was born at 38 weeks' gestation by elective caesarian section because of her mother's pelvic deformity. The pregnancy was normal, but an $x$-ray taken at 34 weeks' gestation showed the fetus to have an abnormally small thorax. At birth she weighed only $2300 \mathrm{~g}$ and appeared small for dates. The thorax was extremely small and the liver and spleen were easily palpable below the costal margins, but no other abnormality was detected.

She gasped immediately, but satisfactory spontaneous respiration was not established and she required intermittent positive pressure ventilation (IPPV) via an endotracheal tube for a few minutes. At 1 hour her condition was satisfactory in $30 \% \mathrm{O}_{2}$ but by $3 \frac{1}{2}$ hours

Received 11 May 1971. her colour was poor in $70 \% \mathrm{O}_{2}$ and she had developed tachypnoea with subcostal retraction and grunting. The lack of sternal recession and the general fixity of the chest were striking. A chest $x$-ray showed a very small thorax and horizontal ribs with expanded costochondral junctions. The extreme narrowness of the upper part of the chest with slight flaring of the lower ribs gave the characteristic 'bell' shape. In addition, however, the lung fields showed the appearance of idiopathic respiratory distress syndrome. At $5 \frac{1}{2}$ hours her condition had deteriorated further and artificial ventilation was necessary. A nasotracheal tube was inserted and a Loosco infant ventilator used to give IPPV. For the next 5 days she required continuous IPPV with high oxygen concentrations, generally $60-80 \%$ but with two periods of two hours on $100 \%$. The blood gases were regularly checked and acidosis corrected as necessary. Subsequently an oxygen concentration of less than $50 \%$ and periods of several minutes off the ventilator were tolerated, but reserve was minimal and any disturbance caused distress and cyanosis. At 2 weeks she breathed spontaneously for two periods of several hours but her condition then deteriorated once again and continuous ventilation was necessary. Chest $x$-rays showed depression of the diaphragm and the development of generalized reticulonodular shadowing with multiple translucent areas. Repeated episodes of oedema and infection required treatment.

At 33 days tracheostomy was performed and she was transferred to a Bird mark 8 ventilator supplied with an oxygen-air mixture by a compressor pump and mixing cylinder (Newman and Evans, 1969). Her condition remained precarious, and frequent severe cyanotic attacks occurred during one of which she suffered a brief period of cardiac arrest.

Respiratory assessment off the ventilator showed that though she made powerful spontaneous respiratory efforts, generating intraoesophageal pressure swings of up to $85 \mathrm{~cm} \mathrm{H}_{2} \mathrm{O}$, the total pulmonary resistance was 
very high, $350 \mathrm{~cm} \mathrm{H}_{2} \mathrm{O} / 1$./sec, and tidal exchange was negligible, approximately $8.0 \mathrm{ml}$.

At the age of 4 months she was transferred to The Hospital for Sick Children, where the same regimen of ventilation was employed. On examination at this time her small rigid chest cage (circumference at nipple line $32.5 \mathrm{~cm}$ ) contrasted with the size of her head (circumference $36.4 \mathrm{~cm}$ ) and distended abdomen. Her limbs were short in relation to her trunk, but no other abnormality was present. She was alert and responsive and when quiet could be adequately ventilated with $30 \%$ $\mathrm{O}_{2}$ at a rate of 50 cycles per minute and a peak inspiratory pressure of $35 \mathrm{~cm} \mathrm{H}_{2} \mathrm{O}$. However, she continued to suffer frequent cyanotic episodes. Chest $x$-rays showed the diaphragm to be almost completely inverted and widespread patchy collapse and consolidation. A transient depression of IgG immunoglobulin, probably physiological, was treated by replacement $\gamma$-globulin injections for two months, after which normal levels were maintained.

During the following weeks it became progressively more difficult to achieve adequate ventilation, and the cyanotic attacks became yet more frequent and severe. Though her small chest size was clearly not the only factor responsible for her respiratory difficulties, it appeared to be playing a significant and possibly a major part. Surgical reconstruction of the chest cage offered the only hope of improvement, and was attempted at the age of 7 months.

Operation (D.J.W.). During induction of anaesthesia the larynx was noted to be too small to accept a 3. $0 \mathrm{~mm}$ uncuffed endotracheal tube. The chest was opened through a tranverse submammary incision. Part of the right eighth rib was removed subperiosteally and the sternum split vertically in the midline. The upper part of the sternum was held apart with the rib which separated the edges of the sternum by $2.5 \mathrm{~cm}$. The rib was perforated at each end and secured with unabsorbable sutures. The ribs and sternum proved very thin and soft, and it was felt that further rib grafts would not be sufficiently strong. Two grafts of Keel sterilized bone matrix were therefore used and secured in a similar manner at the midpoint and at the lower end of the sternum separating the edges by $3.0 \mathrm{~cm}$. Biopsies were taken from the thymus which was normal, and from the left lung which was essentially normal in structure but showed some overinflation with congestion, intra-alveolar fibrin, and a histiocytic response. Static compliance measured before and after the operation showed little change in lung compliance, $6.3 \mathrm{ml} / \mathrm{cm} \mathrm{H}_{2} \mathrm{O}$ before operation and $6.0 \mathrm{ml} \mathrm{H} \mathrm{H}_{2} \mathrm{O}$ after operation, but at the increased volume, the chest wall compliance had fallen from $11.0 \mathrm{ml} / \mathrm{cm} \mathrm{H}_{2} \mathrm{O}$ to $6.0 \mathrm{ml} / \mathrm{cm} \mathrm{H}_{2} \mathrm{O}$.

After the operation there was a great improvement in ease of ventilation and the cyanotic attacks became much less frequent and severe. Spontaneous respiratory efforts were discouraged in the postoperative period by the use of sedation and deliberate overventilation in order to avoid strain on the grafts. Though the bone graft soon became rigid, both Keel grafts worked loose and had to be removed 5 weeks after the operation. However, the upper graft kept the sternal edges separated by approximately $2.5 \mathrm{~cm}$ and the relative ease of ventilation was maintained.

A progressive improvement in her general condition occurred. It became possible to handle, feed, bath, and play with her in a more normal way, and she soon responded with rapid developmental progress.

Several further complications occurred, including the development of pneumothorax, mucus plugging of a bronchus, and repeated episodes of infection, each of which would probably have proved fatal before the operation. Progressive herniation of lung through the sternal defect also occurred, so a canvas jacket with anterior support was used to check the herniation without impeding movement of the ribs. Her general appearance at this time is shown in Fig. 1 and her chest $x$-ray in Fig. 2 and 3.

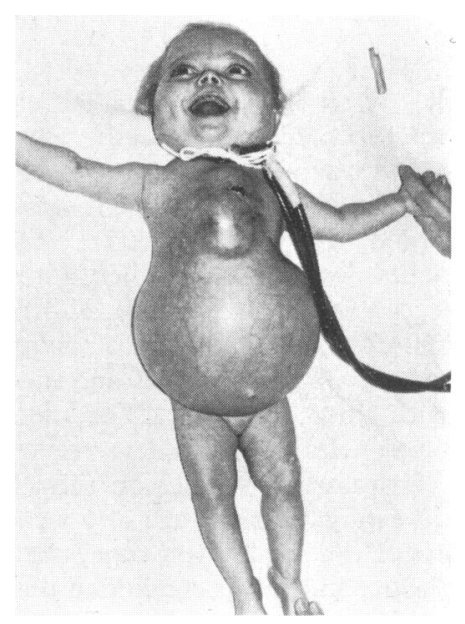

FIG. 1.-General appearance at 9 months (2 months after the first operation), showing the small thoracic cage with herniation of lung through the sternal split. Note also the normal facies, short limbs, and distended abdomen.

Measurements of her spontaneous respiratory efforts continued to show the same pattern of rhythmic intrathoracic pressure swings producing negligible tidal volume. Her virtual flail chest was clearly now an important additional factor limiting her respiratory exchange, the sternal split opening and closing with each effort. Attempts at external fixation were unsuccessful.

At 16 months her length was $75 \mathrm{~cm}$ but her limbs were still disproportionately short-span $68 \mathrm{~cm}$, crownpubis $48 \mathrm{~cm}$, pubis-heel $27 \mathrm{~cm}$. Chest circumference at the nipple-line was $47.5 \mathrm{~cm}$ and the sternal split $5 \mathrm{~cm}$ wide in the nipple line at rest. She had 10 teeth. Apart from the chest and short but radiologically normal limbs, skeletal survey showed no abnormality. She was sitting alone and her manual manipulative skill was improving rapidly. She discovered that by holding 


\section{Chest Reconstruction in Thoracic Dystrophy}

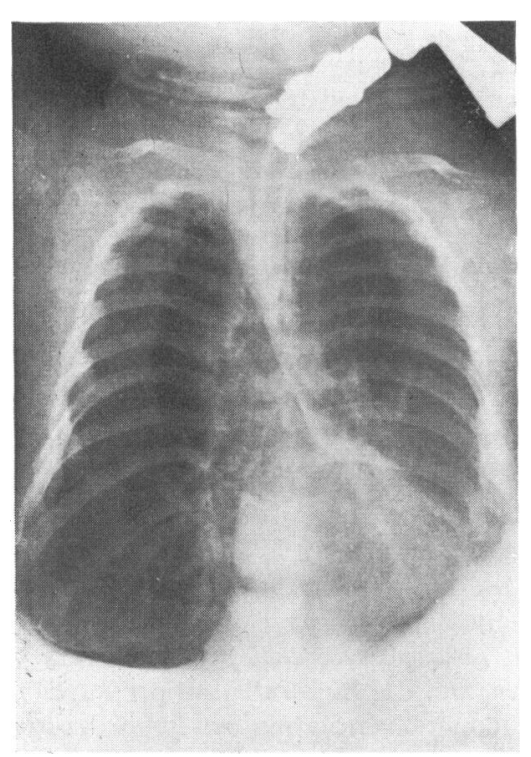

FIG. 2.-Chest $\mathrm{x}$-ray at 9 months showing the thoracic cage after splitting of the sternum. The translucent area over the upper mediastinum is due to the lung herniation. Note also the small right pneumothorax and extreme depression of the diaphragm.

her head and neck in a certain position she could increase the leak around the tracheostomy tube in the inspiratory phase of the ventilator and, using this flow of air, she began to form recognizable words. A tracheostomy tube was modified to provide a gas flow from another source to pass continuously over her larynx but she preferred to use the leak. Developmental assessment at 18 months showed an atypical pattern of development with scattered abilities; personal-social (Griffiths) 12 months, sensorimotor understanding 11 months, level of play 8 to 9 months, verbal comprehension 15 months, expressive language 12 months, symbolic recognition 15 months (Dr. J. Reynell). A cot was modified to carry the ventilator so that she could be mobile. Her parents spent most of every day with her and gradually took over all aspects of her day-to-day care, including changing the tracheostomy tube and adjusting the ventilator.

At 20 months an attenpt was made to stabilize the chest cage. Static compliance measured before the operation showed lung compliance $20.3 \mathrm{ml} / \mathrm{cm} \mathrm{H}_{2} \mathrm{O}$ and chest wall compliance $72 \cdot 0 \mathrm{ml} / \mathrm{cm} \mathrm{H}_{2} \mathrm{O}$. Through the same incision the left seventh and right eighth ribs were resected subperiosteally and fixed with unabsorbable sutures to the sternal edges and adjoining ribs at the mid and lower points of the sternum. A woven Dacron patch was shaped to fill the defect and stitched around the margin below the grafts to contain the lung herniation. Static compliance 3 weeks after the operation showed that the lung compliance was virtually

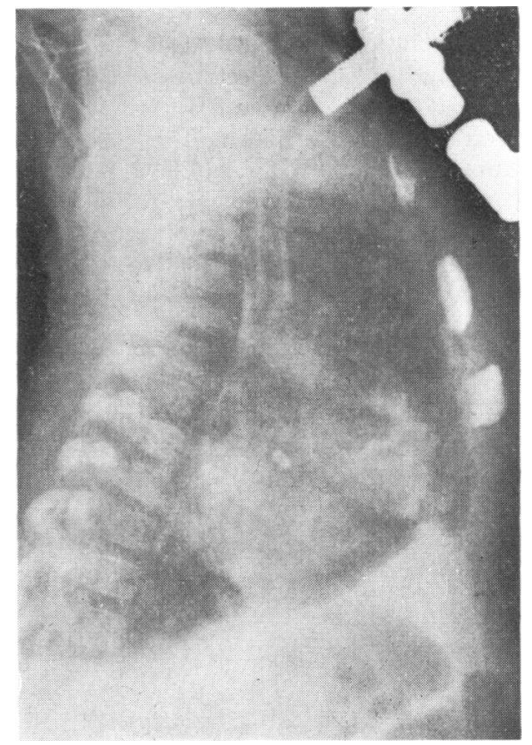

FIG. 3.-Lateral chest $\mathrm{x}$-ray at 9 months showing the three grafts.

unchanged at $18 \cdot 2 \mathrm{ml} / \mathrm{cm} \mathrm{H}_{2} \mathrm{O}$ but that the chest wall compliance had fallen to $29.5 \mathrm{ml} / \mathrm{cm} \mathrm{H}_{2} \mathrm{O}$.

The grafts took satisfactorily. Her spontaneous respiratory efforts now showed a considerable improvement in tidal volume to $35 \mathrm{ml}$, minute volume $950 \mathrm{ml}$, with a reduction in the total pulmonary resistance to $235 \mathrm{~cm} \mathrm{H}_{2} \mathrm{O} / 1$./sec. However, this remained grossly inadequate for her needs and she could tolerate removal from the ventilator for approximately 4 minutes only.

At 23 months she was transferred home. Only minor modifications of the house were necessary to accommodate the necessary apparatus. The ventilator was activated with air from a compressor pump, and oxygen enrichment could be provided from a cyclinder if necessary. All apparatus was duplicated in case of failure and the ventilator could be run on compressed air from cyclinders if the electrical supply failed. 24hour nursing cover was provided by the parents and one untrained helper and there were always two people in the house.

She continued to make good progress. At 26 months her length was $84 \mathrm{~cm}$, span $75 \mathrm{~cm}$, crown-pubis $53 \mathrm{~cm}$, pubis-heel $31 \mathrm{~cm}$, head circumference $49.5 \mathrm{~cm}$, chest circumference $50.5 \mathrm{~cm}$. She was friendly, responsive, and playful. Reassessment at 26 months showed that her abilities had improved rapidly to hand-eye 19 months, performance 20 months; and her language development to verbal comprehension 21 months, expressive language 24 months (Drs. J. Reynell and K. S. Holt). She was able to form a number of twoand three-word phrases during the inspiratory phase of the ventilator. She was attempting some building and managed simple puzzles. She walked with support. 
She had also learnt several other tricks, for example by disconnecting the ventilator lead from her tracheostomy stoma she could get instant attention!

A further stabilization of the anterior chest wall was made when she was 30 months old. The lower grafts were secured to the Dacron patch and the diaphragm stitched to its lower edge. Four weeks after this procedure she achieved a tidal volume of $100 \mathrm{ml}$ with a pressure swing of $15 \mathrm{~cm} \mathrm{H}_{2} \mathrm{O}$ and was able to manage 15 minutes off the ventilator.

\section{Discussion}

This family is unique among reported cases of thoracic dystrophy as no other instance of mother and children showing similar skeletal deformities has been recorded. In most cases the condition is probably inherited as an autosomal recessive character. The small larynx present in mother and both children is another feature that has not previously been described. However the skeletal changes, and the histology of the costochondral junctions in the first child, are typical of thoracic dystrophy.

Because of the damage to her lungs due to respiratory distress syndrome, oxygen toxicity, repeated infection, and the effects of prolonged IPPV, it is not possible to assess how severely this child's lung function would have been compromised by the thoracic deformity alone. However, her chest deformity seems to be comparable to that of her brother who survived only six weeks. Considerable growth of her ribs has taken place, and it is possible that by now her chest deformity alone would no longer be a problem. Patients with this condition who survive the first year may, like the mother of these two children, make good progress.

Two previous attempts to improve this condition surgically by releasing a number of ribs at the costochondral junction were unsuccessful (Razzi, Rosso, and Durand, 1965; Durand et al., 1965). Simple calculations suggested that a considerable increase in thoracic volume would be achieved by splitting the sternum. Thus, assuming the thorax to be cylindrical, with circumference $33 \mathrm{~cm}$ and length $10 \mathrm{~cm}$, a $3 \mathrm{~cm}$ increase in circumference would cause approximately a $25 \%$ increase in thoracic volume. If the lungs retained the capacity to expand which was suggested by our necropsy study on the sib, such an increase in thoracic volume would result in a considerable increase in lung volume. In order to preserve the function of the thoracic cage, however, the chest wall must remain stable and this posed technical problems. Various methods of fixation were considered, including the use of metal struts or quick-setting acrylic resin, but it was felt that bone grafts would be most satisfactory. At the first attempt the ribs and sternum proved to be very flimsy. Sterilized bone matrix had to be used which did not hold the stitches and soon worked loose. A satisfactory result was achieved at the second attempt when the ribs and sternum had become stronger. During the postoperative period it was clearly desirable that as little strain as possible was put on the grafts. However, total paralysis was not used as it was felt that the risks involved outweighed those of dislodging the grafts.

At present she still needs ventilatory support because of the associated lung damage. The pathophysiological changes are similar to those we have seen in a number of infants following prolonged IPPV (Barnes et al., 1969a). All the infants had extremely high airways resistance, so that spontaneous respiratory efforts produced very poor tidal volumes, and the high inflation pressures needed to give adequate ventilation led to progressive overinflation of the lungs. However 4 of 6 children who each required artificial ventilation for over six months have eventually been weaned from the ventilator.

A remarkable feature of this child's progress has been her good developmental progress within the limitations imposed by the ventilator. This is especially surprising in view of the innumerable episodes of severe hypoxia which occurred in the early months.

The recent improvements in the techniques of IPPV which permit the indefinite survival of patients with severely damaged lungs raise difficult ethical, social, and economic problems. Though, in retrospect, the tremendous and disproportionate expenditure of time and money on this child may be questioned, at no time did the situation look so hopeless that active treatment could have been withdrawn.

Only the ability and willingness of intelligent parents to devote so much of their lives to the care of this child enables her to be managed at home.

The improvement in the time she tolerates off the ventilator is encouraging, and we hope that the capacity for growth of the lungs and chest will prove sufficient to allow her to lead an independent existence in the future.

We wish to acknowledge the vital part played by the late Dr. D. G. Cottom, Dr. C. G. H. Newman and the staff of the Special Care Nursery at St. Thomas's Hospital in the early care of this child.

\section{REFERENCES}

Barnes, N. D., Glover, W. J., Hull, D., and Milner, A. D. (1969a). Effects of prolonged positive-pressure ventilation in infancy. Lancet, 2, 1096. 
Barnes, N. D., Hull, D., and Symons, J. S. (1969b). Thoracic dystrophy. Archives of Disease in Childhood, 44, 11.

Durand, P., Razzi, A., Mastragostino, S., and Gimelli, F. A. (1965). La distrofia toracica adfissiante (malattia di Jeune): tentativo d'intervento chirurgico sulla gabbia toracica. Minerva Pediatrica, 17, 1437.

Jeune, M., Beraud, C., and Carron, R. (1955). Dystrophie thoracique asphyxiante de caractère familial. Archives Francaises de Pédiatrie, 12, 886.
Newman, C. G. H., and Evans, R. S. (1969). Device for control of oxygen concentration with Bird respirator. Lancet, 1, 28.

Razzi, A., Rosso, C., and Durand, P. (1965). Contributo anatomopatologico alla distrofia toracica asfissiante del lattante (malattia di Jeune) e considerazioni sull'utilità terapeutica dell'intervento chirurgico sulle coste. Minerva Pediatrica, 17, 1823.

Correspondence to Dr. David Hull, Institute of Child Health, 30 Guilford Street, London W.C.1. 